\title{
Quality and Shelf-Life Evaluation of Packaged Biscuits Marketed in Bangladesh
}

\author{
K. Chowdhury, S. Khan, R. Karim, M. Obaid and G.M.M.A. Hasan \\ Institute of Food Science \& Technology (IFST), BCSIR, Dhaka-1205
}

\begin{abstract}
Five different brands of locally produced biscuits and five brands of foreign biscuits were collected from the market. All these biscuits were stored at ambient condition $\left(30^{\circ} \mathrm{C}\right.$, and $\left.60 \% \mathrm{RH}\right)$ for 3 months. The changes in water activity, moisture and their consequences on sensory qualities like texture, color, flavor and overall acceptance were investigated in every month. Test of packaging materials were also carried out for each brand of packed biscuits. Moisture and water activity values have been increased with time for all the samples whereas sensory scores decreased. However, all the foreign and local biscuit samples were found acceptable under the study period but only one local biscuit was found unsalable.
\end{abstract}

Key words : Biscuit, Moisture, Water activity, Sensory quality, Packaging materials, Storage condition and Shelf life.

\section{Introduction}

Bakery products are the important source of nutrients. Different types of bakery products include bread, biscuits, pastries, cakes, buns, rusk, etc. Biscuits are the lowest cost processed food. They are easy to use during travel or at home because of its availability in variety of pack sizes (http://www.envis-icpe.com/icpefoodpackaging/pdfs/7_bakery.pdf). Biscuits are small baked products made principally from flour, sugar and fat (Manley, 1998). The word "Biscuit" is of French origin and means "twice cooked". Nowadays, most biscuits are baked only once (Lallemand Inc., 2000). Biscuits typically have a moisture content of less than $4 \%$ and have a long shelf life of six months or more (Manley, 1998).

Shelf life is an important property of any food and is of interest to everyone in food chain from producer to consumer. Well planned and conducted consumer acceptability tests in the form of appropriate sensory analysis, is an important part of the shelf life evaluation of any product (Man and Jones, 1994). Moisture and water vapor transfer act as key influencing factor for shelf life (Steele, 2004). Physicochemical changes in food during storage can cause loss of shelf-life resulting deterioration of its quality (Ooraikul and Stiles, 1991).

Water is a constituent of food which affects food safety, stability, quality and physical properties (Lewicki, 2004). Increased moisture of food due to water sorption from the atmosphere or by mass transport from neighboring compo- nents results in a soggy, soft texture (Lewicki et al, 2004). Biscuits are fragile and characterized by a low moisture content, low water activity and are highly hygroscopic (http://www.envis-icpe.com/icpefoodpackaging/pdfs/7_bakery.pdf).

Water activity is another critical factor in determining the shelf life of product. Rates of exchange of moisture through the packaging material and the rate of change in water activity of food towards a critical limit will determine the shelf life of a product (Nieuwenhuijzen et al, 2008). Water activity brings a supplement of information as it accounts for the availability of water for degradation reactions (Mathlouthi, 2001). It has become the basic controlling factor in the preservation of foods against microbiological, chemical and physical deterioration (Van Den Berg \& Bruin, 1981). Many foods have a water activity level in the range of 0.3 for very dry foods to 0.99 for moist fresh foods (Worobo and PadillaZakour, 1999).

Off-flavors, off-odors and loss of crispiness in packaged food are the major cause of consumer rejection. These might be caused by oxidative rancidity of packaged food, permeation, migration and reactions between packaging components with the food components (Ackermann et al, 1995).

Most food products rely on their particular packaging to achieve their expected shelf life (Steele, 2004). The shelf-life of biscuits depends upon inherent characteristics of the prod- 
uct, barrier and other functional properties of the packaging material, packaging operations adopted, distribution and storage patterns followed, and lastly economic considerations (http://www.envis-icpe.com/icpefoodpackaging/pdfs/ 7_bakery.pdf). In modern age, food packaging has become very important to protect the product from contamination by macro and microorganisms and their filth, prevention from loss or gain of moisture, shielding the product from oxygen and to facilitate handling (Ball, 1960). Packaging also increases sale by creating brand image that the buyer usually recognizes and draw attention of better printing quality and glossiness (Peter and Axtell, 1993).

The present work was undertaken to evaluate the quality and shelf life of some biscuits from popular companies of home and abroad available in the local market. The aim was to investigate the relation between moisture, water activity and sensory quality such as color, flavor textures etc as well as the packaging materials including storage condition. Another target was the assessment of the packaging quality of locally and foreign packed biscuits.

\section{Materials and Methods}

\section{Materials}

Ten different brands of biscuits from ten different wellknown companies - five from local companies and five from foreign companies were selected as materials of this study. Attempt has been made to select commonly consumed nationally available brand. From each brand, four packets of biscuits having same date of production were purchased from the market and stored under ambient condition for 3months. Five different local brands were coded as LA, LB, LC, LD, and LE whereas five different foreign brands were coded as FA, FB, FC, FD, and FE. Analyses for water activity, moisture content and sensory evaluations were done at one-month interval starting from zero month during the period between May 2008 to August 2008. All estimations were done in triplicate.

\section{Methods}

\section{a) Test methods of Biscuits:}

i) Moisture: The moisture content was determined by using an electronic Moisture Analyzer (Sartorius MA30, Japan).

ii) Water Activity (aW): Water activity was determined by Water Activity Analyzer-TH-500 Aw Sprint, Novasina,
Switzerland. The water activity scale extends from 0.0 (bone dry) to 1.0 (pure water). Aw represents the ratio of the water vapor pressure of the food to the water vapor pressure of the pure water under the same conditions and expressed as a fraction. If we multiply the ratio by 100 , we obtain the equilibrium relative humidity (ERH) that the food would produce if enclosed in air in a sealed container at constant temperature. Thus a food with water activity (aW) of 0.7 would produce an ERH of $70 \%$ (Worobo and Padilla-Zakour (1999).

III) Sensory Evaluation: Sensory evaluation was carried out every month for each brand of biscuit. A nine point hedonic scale (Peryam \& Pilgrim, 1957) was used to test for flavor, texture, color and overall acceptability of the biscuits.

The degree of likeliness to which a product was expressed as

Like/Dislike Points

Like extremely 9

Like very much 8

Like moderately 7

Like slightly 6

Neither like nor dislike $\quad 5$

Dislike slightly 4

Dislike moderately 3

Dislike very much 2

Dislike extremely 1

A seven member's panel of IFST, BCSIR, has performed sensory evaluation. The same panel members participated in the evaluation session every month starting from zero month. The test was conducted in the laboratory of Oilseed \& Lipid Technology Section, IFST, BCSIR. Five different local brands and five different foreign brands of samples were presented separately to each of the panelists for evaluation. A mean evaluation score of each attribute was repeated for each brand.

\section{IV) Packaging Material Study}

a) Thickness: The thickness of the packaging material was measured by electronic thickness gauge/meter, ModelB-1, TOYO SEIKI, LTD, Japan.

b) Material Identification: Identification of the packaging material of each brand of biscuit was compared by Fourier Transform Infrared Spectrophotometer (FTIR), Shimadzu, JAPAN. 


\section{Results and Discussion}

In the present work, the quality change of the biscuits stored at ambient condition $\left(30^{\circ} \mathrm{C}\right.$ and $\left.60 \% \mathrm{RH}\right)$ for three months were evaluated by monitoring the moisture, water activity, sensory acceptability and packaging material.

Moisture: Moisture content is the total moisture i.e. bound plus free water present in the sample (Worobo and PadillaZakour, 1999). It is the decisive criteria for the organoleptic properties and acceptability by the consumers (http:/ /www.envis-icpe.com/icpefoodpackaging/pdfs/7_bakery. pdf). Figure 1a shows that the initial moisture content of different locally produced biscuits varies from $1.78 \%$ to $4.2 \%$. The highest initial moisture content was found in LB (4.2\%) which was a cream biscuit and the second highest moisture in $\mathrm{LD}(3.83 \%)$ was a sugar coated butter coconut cookie. The moisture content of biscuits has shown an increasing trend with time. During the first month, no marked increase in moisture content was observed for local biscuits which ranges from 1.93 to $4.22 \%$. But during the second month, moisture gain for these samples was much higher ranging from 2.81 to $4.64 \%$. In the third month, the increase was small compared to second month ranging from 2.98 to
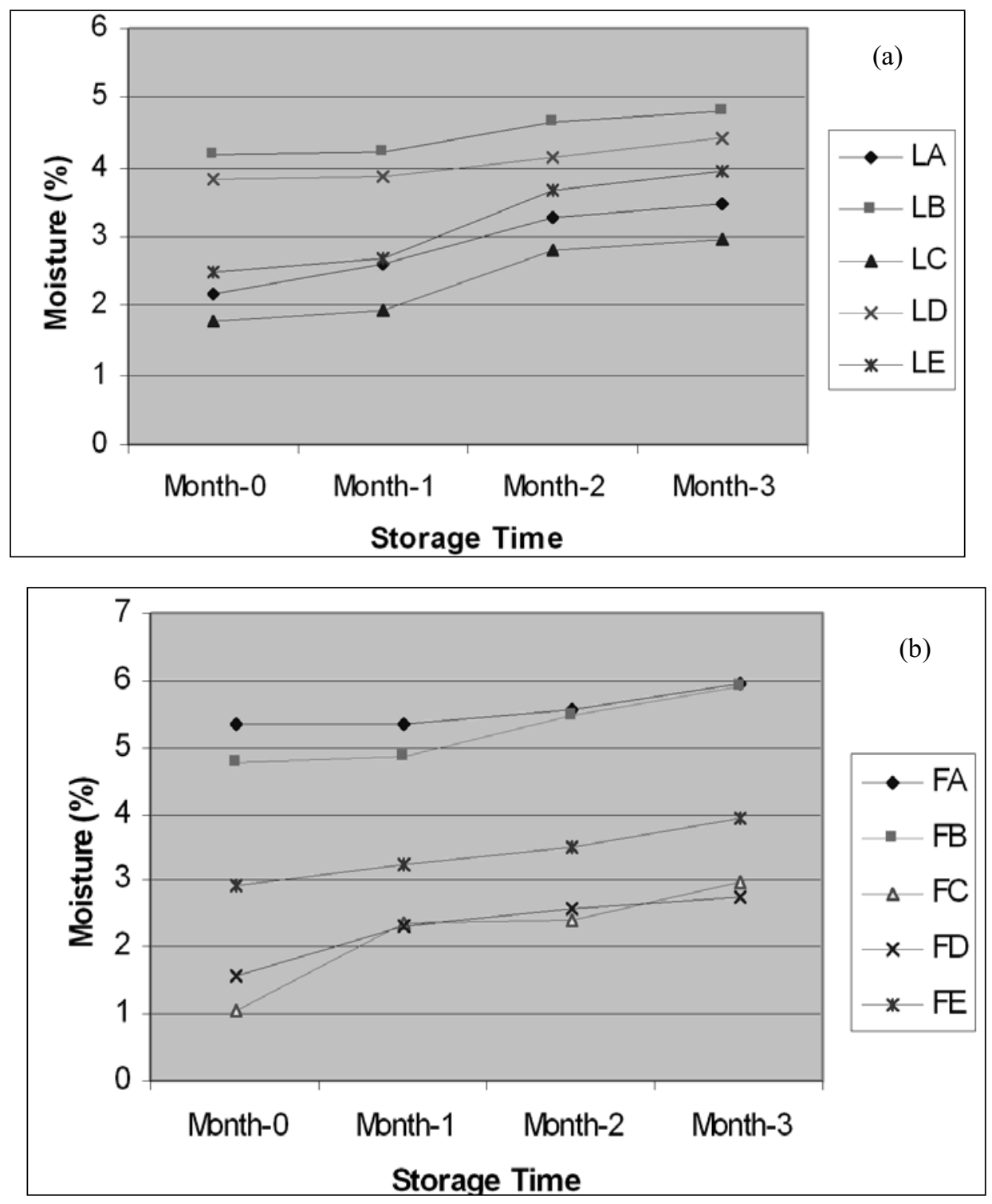

Fig. 1: Changes in moisture content in different brands of biscuits - (a) Local Biscuits LA - LE and (b) Foreign Biscuits FA -FE 
$4.81 \%$. In comparison with the initial values of moisture content of local biscuits, the total increase was significant. However, the rate of moisture gain from environment was not same for all local biscuits. In LA, LC and LE, moisturecontent increased around $60 \%$ but for LB and LD, it was only about $15 \%$.

For foreign biscuits the increasing trend of moisture content was a little bit different for different biscuits (Fig 1b). Figure $1 \mathrm{~b}$ shows that initially the moisture content of these biscuits ranged from 1.05 to $5.33 \%$. In the first month, the increase was negligible for FA (5.33 to 5.34) and FB (4.75 to 4.84), medium for FD (1.59 to 2.32) and FE (2.94 to 3.24) and abruptly high for FC (1.05 to 2.36). In the second month, these biscuits showed a totally different scenario. FC had a negligible increase (2.36 to 2.39), but FA (5.34 to 5.56), FD (2.32 to 2.56) and FE (3.24 to 3.48) showed medium increase and a high increase was observed for FB (4.84 to 5.48). In the third month moisture content increased in another different pattern ranging from 2.74 to $5.93 \%$ (Fig 1b).

After leaving the oven the moisture remaining in biscuits is unevenly distributed. Biscuits absorb moisture from the atmosphere which usually leads to softening of the biscuit (Dunn and Bailey, 1928). The speed of moisture pick-up is related to the ambient conditions (Manley, 1998). The find
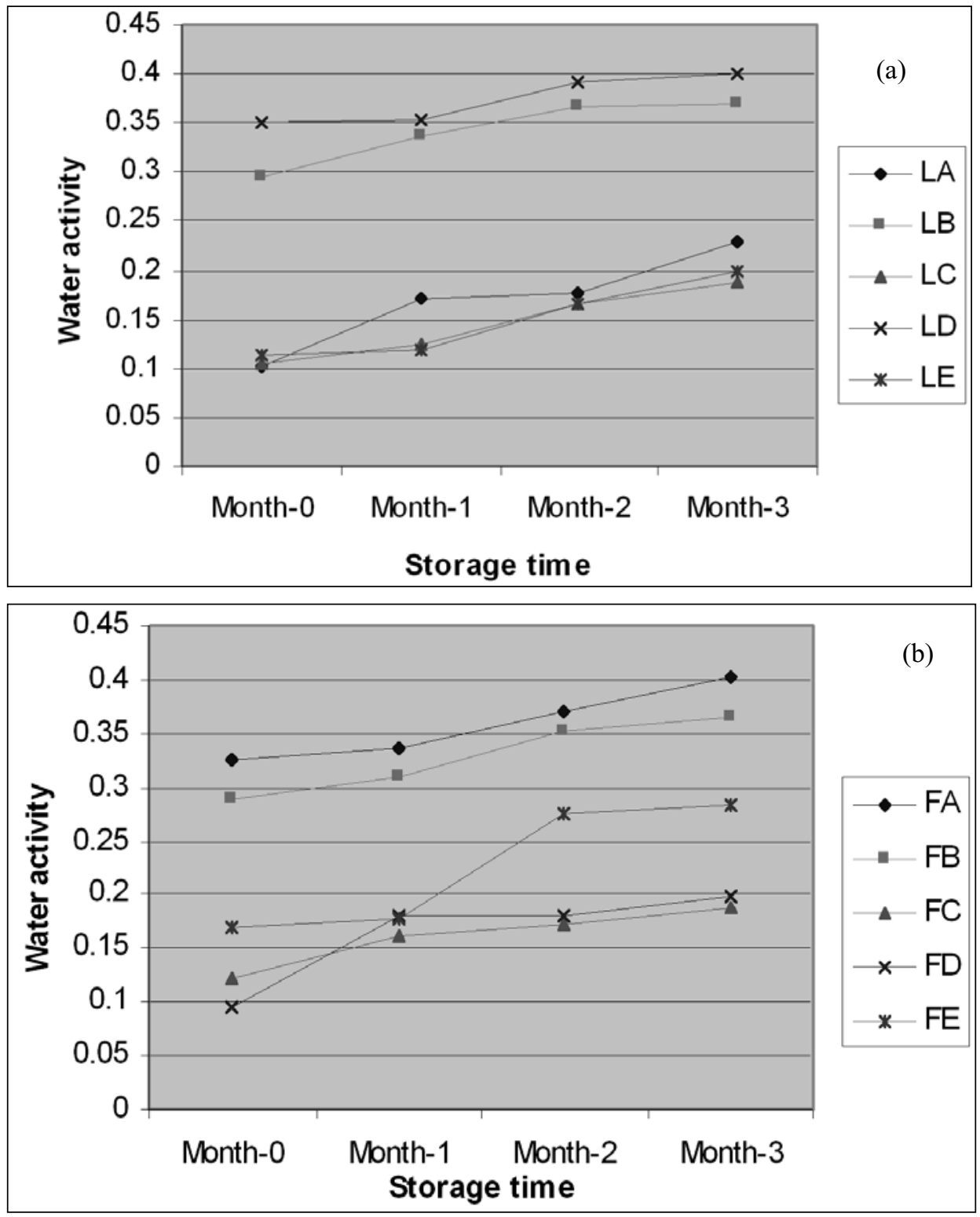

Fig. 2: Changes in water activity in different brands of biscuits - (a) Local Biscuits LA - LE and (b) Foreign Biscuits FA -FE 
ings of increased moisture correlate with the sensory evaluation of the present study. The gain of moisture varied for local biscuits between 14.5 to $67.4 \%$ whereas for imported foreign biscuits it varied from 11 to $182 \%$. The range of moisture gain for foreign biscuits is wider than that of local biscuits. Local biscuits are made suitable for native environment whereas imported biscuits are exposed to different environment and thus gain more moisture.

\section{Water activity}

Water activity is the measurement of free moisture and is usually expressed as "aw" or percentage Equilibrium Relative Humidity (\% ERH) (Worobo and Padilla-Zakour, 1999). Freshly baked biscuits usually have water activity about 0.3 (Wade, 1988). Figure 2 shows the changes in aw values of both the local biscuits (Figure 2a) and the foreign biscuits (Figure $2 b$ ) during 3 months storage period. Among the local biscuits, initial aw levels in $\mathrm{LD}(0.35)>\mathrm{LB}(0.295)$ $>\operatorname{LE}(0.114)>\operatorname{LC}(0.105)>$ LA $(0.101)$. No particular increasing pattern has been observed for water activity of the local biscuits. But an irregular ascending trend has been found for all five local biscuits over 3 months period.
Another irregular increasing trend of "aw" value has also been observed for foreign biscuits starting from a range of 0.096 to 0.326 in initial stage for FA, FB, FC, FD and FE. After 3 months, this range was found from 0.188 to 0.402 for the same biscuits. This finding indicates that the aw of both types of biscuits has been within the critical aw limit of 0.43 for biscuits and crackers (Labuza and Contreras-Medellen, 1981).

Toledo (1991) stated that if water activity (aw) value is lower than 0.70 it prevents microbiological damage, but to prevent deteriorative chemical and biochemical reactions, it is necessary that the dryness be reduced to a water activity value lower than 0.3. (Roudaut et al, 1998, 2000).

\section{Sensory Analysis}

Table I reveals the detailed sensory analysis of the packed local biscuits (LA - LE) during 3 months period. All five biscuits have production date between February, 2008 to April 2008. But according to the label on packets, there is variation in shelf-life of these biscuits. LC has the label with 6 months shelf-life, LB has 10 months whereas LA, LD \& LE have labels of 1 year shelf-life.

Table I: Sensory Evaluation Scores of different brands of Local Biscuits stored at ambient condition for 3-months.

\begin{tabular}{l|c|c|c|c|c|c}
\hline \multicolumn{1}{c|}{ Attributes } & Storage month & LA & LB & LC & LD & LE \\
\hline \multirow{4}{*}{ Color } & 0 & $7.71 \pm 0.82$ & $6.85 \pm 1.07$ & $8.00 \pm 0.82$ & $8.28 \pm 0.48$ & $7.28 \pm 0.48$ \\
& 1 & $7.71 \pm 0.49$ & $6.71 \pm 1.11$ & $8.00 \pm 0.82$ & $8.00 \pm 1.00$ & $7.00 \pm 5.57$ \\
& 2 & $7.43 \pm 1.13$ & $6.57 \pm 1.39$ & $7.86 \pm 0.89$ & $8.00 \pm 0.82$ & $6.71 \pm 1.25$ \\
& 3 & $7.43 \pm 0.75$ & $6.57 \pm 1.27$ & $7.57 \pm 0.97$ & $7.57 \pm 1.27$ & $6.71 \pm 0.95$ \\
\hline \multirow{4}{*}{ Flavor } & 0 & $7.57 \pm 0.97$ & $5.71 \pm 2.49$ & $8.00 \pm 0.82$ & $7.86 \pm 0.69$ & $7.14 \pm 0.89$ \\
& 1 & $7.57 \pm 0.53$ & $4.86 \pm 1.46$ & $7.86 \pm 0.89$ & $7.71 \pm 1.11$ & $6.86 \pm 2.03$ \\
& 2 & $7.28 \pm 0.49$ & $4.71 \pm 2.06$ & $7.57 \pm 0.97$ & $7.57 \pm 1.13$ & $6.86 \pm 1.21$ \\
Texture & 3 & $7.14 \pm 1.06$ & $4.28 \pm 1.25$ & $7.57 \pm 0.78$ & $7.00 \pm 1.29$ & $6.57 \pm 1.27$ \\
& 0 & $7.43 \pm 0.75$ & $6.57 \pm 1.27$ & $8.42 \pm 0.53$ & $7.86 \pm 0.89$ & $7.00 \pm 0.82$ \\
& 1 & $7.28 \pm 0.75$ & $6.00 \pm 2.64$ & $8.00 \pm 1.00$ & $7.43 \pm 0.97$ & $6.86 \pm 1.34$ \\
& 2 & $7.00 \pm 1.63$ & $5.85 \pm 0.69$ & $7.71 \pm 1.11$ & $7.28 \pm 0.48$ & $6.86 \pm 1.07$ \\
Taste & 3 & $6.85 \pm 1.06$ & $5.00 \pm 1.91$ & $7.71 \pm 0.75$ & $6.57 \pm 1.51$ & $6.43 \pm 0.78$ \\
\hline & 0 & $7.57 \pm 0.78$ & $5.42 \pm 1.51$ & $8.14 \pm 0.89$ & $7.71 \pm 1.11$ & $7.00 \pm 1.15$ \\
& 1 & $7.28 \pm 0.95$ & $5.28 \pm 2.88$ & $8.00 \pm 0.82$ & $7.57 \pm 0.78$ & $6.86 \pm 0.69$ \\
Overall & 2 & $7.28 \pm 0.75$ & $5.00 \pm 1.15$ & $8.00 \pm 0.82$ & $7.43 \pm 0.97$ & $6.71 \pm 0.75$ \\
acceptance & 3 & $7.14 \pm 0.69$ & $4.85 \pm 1.67$ & $7.71 \pm 0.95$ & $7.14 \pm 1.34$ & $6.57 \pm 0.97$ \\
\hline & 0 & $7.28 \pm 0.48$ & $5.42 \pm 1.51$ & $8.14 \pm 2.37$ & $7.71 \pm 0.75$ & $7.00 \pm 1.15$ \\
\hline
\end{tabular}

Scores are based on a 9 point hedonic scale where Score of $9=$ Like extremely $5=$ neither like or dislike $1=$ Dislike extremely. 
Observing the texture, flavor and crispiness of the stored local biscuits in table 1 it can be told that the initial sensory score of LB was very poor $(5.42 \pm 1.51)$ and the highest score belonged to LC $(8.14 \pm 2.37)$. This corresponds to the highest initial moisture content of LB (4.2) and the lowest initial moisture content of LC (1.78). The sensory score for other three local biscuits, LA, LD \& LE were $7.28 \pm 0.48$, $7.71 \pm 0.75$ and $7.00 \pm 1.15$, respectively. At the first month change in sensory score was observed only for some local biscuits (LB, LC \& LE) and not for LA \& LD. But at the end of study period (i.e. after 3 months storage), overall acceptance score of local biscuits LA to LE were $7.14 \pm 0.69$, $5.00 \pm 1.00,7.71 \pm 0.95,7.14 \pm 1.34$ and $6.42 \pm 0.69$, respectively. Therefore, during storage period the taste as well as the overall quality of the biscuit LB has been deteriorated \& finally becomes unacceptable from the sensory standpoint. Local biscuits LA, LC, LD \& LE have been found accept able where LC is of superior quality.

Table II shows the sensory evaluation scores of five foreign biscuits stored at ambient condition for 3 months. At zero month acceptance score of these biscuits (FA - FE) ranges from $7.14 \pm 1.06$ to $8.14 \pm 0.69$. Thus all the five brands of imported biscuits are of good quality from the very beginning. At the end of storage period, the sensory score declined for all the five biscuits (FA - FE) ranging from $6.71 \pm 0.75$ to $7.43 \pm 1.13$.

However comparative study between foreign and local biscuits shows that all the foreign and local biscuits are within acceptable range for sensory score whereas only one local biscuit (LB) has crossed the marginal acceptability score. The increasing trend of sensory score from zero month to third month of all brands of foreign and local biscuits complies with the increasing trend of moisture and water activity. These results are similar to those Katz and Labuza (1981), Seymour and Hamann (1988) and Sauvageot and Blond (1991). Each of these researchers, studying different types of crisp foods, determined that as the water activity is increased, sensory crispness is decreased.

\section{Packaging Material Study}

A wide range of packaging materials are used to pack biscuits. Packaging material study has been carried out to observe the effects of packaging materials on the stability of

Table II: Sensory Evaluation Scores of different brands of Foreign Biscuits stored at ambient condition for 3-months.

\begin{tabular}{l|c|c|c|c|c|c}
\hline \multicolumn{1}{c|}{ Attributes } & Storage month & FA & FB & FC & FD & FE \\
\hline \multirow{4}{*}{ Color } & 0 & $8.28 \pm 0.75$ & $7.43 \pm 1.27$ & $8.28 \pm 0.48$ & $8.00 \pm 0.57$ & $8.14 \pm 0.89$ \\
& 1 & $8.00 \pm 0.82$ & $7.43 \pm 0.78$ & $8.14 \pm 0.69$ & $7.86 \pm 0.89$ & $8.00 \pm 0.82$ \\
& 2 & $7.86 \pm 0.69$ & $7.28 \pm 0.95$ & $8.14 \pm 0.69$ & $7.43 \pm 0.97$ & $7.86 \pm 1.06$ \\
& 3 & $7.86 \pm 0.38$ & $7.28 \pm 0.75$ & $8.00 \pm 0.82$ & $7.43 \pm 0.78$ & $7.86 \pm 0.69$ \\
\hline \multirow{5}{*}{ Flavor } & 0 & $7.43 \pm 0.53$ & $7.14 \pm 1.06$ & $8.28 \pm 0.75$ & $7.86 \pm 0.69$ & $7.43 \pm 1.27$ \\
& 1 & $7.28 \pm 0.75$ & $7.14 \pm 0.89$ & $8.00 \pm 1.00$ & $7.57 \pm 0.78$ & $7.43 \pm 0.97$ \\
& 2 & $7.28 \pm 0.75$ & $6.71 \pm 1.60$ & $7.86 \pm 1.34$ & $7.28 \pm 0.75$ & $7.28 \pm 0.48$ \\
Texture & 3 & $6.71 \pm 0.95$ & $6.28 \pm 0.75$ & $7.71 \pm 0.48$ & $7.14 \pm 0.69$ & $7.00 \pm 0.57$ \\
\hline & 0 & $7.86 \pm 0.69$ & $7.28 \pm 0.75$ & $8.14 \pm 0.69$ & $8.14 \pm 0.69$ & $7.86 \pm 0.69$ \\
& 1 & $7.43 \pm 0.53$ & $6.86 \pm 0.69$ & $8.00 \pm 0.82$ & $8.00 \pm 0.00$ & $7.86 \pm 0.69$ \\
Taste & 3 & $7.14 \pm 1.06$ & $6.43 \pm 0.79$ & $7.86 \pm 0.89$ & $7.86 \pm 0.89$ & $7.57 \pm 1.13$ \\
& 0 & $7.14 \pm 0.89$ & $6.14 \pm 1.46$ & $7.71 \pm 0.48$ & $7.71 \pm 1.11$ & $7.28 \pm 0.95$ \\
\hline & 1 & $7.14 \pm 0.69$ & $7.14 \pm 1.06$ & $8.00 \pm 0.57$ & $7.86 \pm 0.69$ & $7.86 \pm 1.06$ \\
Overall & 2 & $7.28 \pm 0.75$ & $6.71 \pm 0.75$ & $7.86 \pm 0.69$ & $7.57 \pm 0.97$ & $7.57 \pm 0.78$ \\
acceptance & 3 & $7.14 \pm 1.46$ & $6.57 \pm 0.78$ & $7.71 \pm 0.48$ & $7.14 \pm 0.95$ & $7.43 \pm 0.78$ \\
\hline
\end{tabular}

Scores are based on a 9 point hedonic scale where Score of 9=Like extremely 5=neither like or dislike 1=Dislike extremely. 
biscuits during ambient storage. Table III reveals thickness variation of the packaging materials used for packaging of both local and foreign biscuits. Some biscuits have double packages (external and internal packages) while others have single package.

\section{i) Thickness Study}

Table III shows that the thickness of external packaging materials of local biscuits ranges between $0.049-0.056$ millimeters. This range is not so significant revealing that they are mostly uniform. Again thickness of internal packages of local biscuits LB, LD and LE ranges from 0.031 to 0.274 . LA and LC have single outer package. of all the brands of biscuits was done. IR spectrum of functional groups of each packaging material is unique. Packaging materials are polymer compounds. An organic compound is identified by finding a reference or transmittance IR spectrum that matches that of the unknown compound (Settle, 1997).

Figure 3 demonstrates the FTIR spectra of standard reference materials of BOPP (Biaxially oriented polypropylene), LLDPE (Linear low density polyethylene), PVC (Polyvinyl chloride) and polystyrene. Most biscuits have double packages and a few have single package. Different packages of these biscuits have shown different spectra.

Table III: Study of Thickness of Packaging Materials of Local Biscuits

\begin{tabular}{l|c|c|c|c|c}
\hline \multirow{2}{*}{} & \multicolumn{5}{|c}{ Thickness } \\
\cline { 2 - 6 } & LA & LB & LC & LD & LE \\
\hline External Package & $0.052 \pm 0.002$ & $0.056 \pm 0.001$ & $0.049 \pm 0.0027$ & $0.053 \pm 0.001$ & $0.053 \pm 0.0019$ \\
Internal Package & - & $0.034 \pm 0.001$ & - & $0.031 \pm 0.002$ & $0.274 \pm 0.01$ \\
\hline
\end{tabular}

On the contrary from table IV for foreign biscuits, the range is between $0.043-0.36$ millimeters. The thickness variation of external packaging materials of foreign biscuits is extremely wide. For foreign biscuits (FA - FE) thickness variation of inner packaging ranges between $0.052-0.59$. Such wide thickness variation reveals the use of different types of packaging materials for different biscuits.
Among five brands of local biscuits, LA and LC have single package and LB, LD \& LE have double packages. Figure 4 shows the FTIR spectra of outer packages of all five brands of local biscuits which have been found almost identical. The first IR absorption in these materials has been found in 3100$2700 \mathrm{~cm}^{-1}$ absorbance region which has been expected to consist solely of methylene stretches and bends $(\mathrm{C}-\mathrm{H}$ stretch

Table IV : Study of Thickness of Packaging Materials of Foreign Biscuits

\begin{tabular}{l|c|c|c|c|c}
\hline & \multicolumn{5}{|c}{ Thickness } \\
\cline { 2 - 6 } & FA & FB & FC & FD & FE \\
\hline External Package & $0.064 \pm 0.0019$ & $0.043 \pm 0.001$ & $0.36 \pm 0.0077$ & $0.045 \pm 0.002$ & $0.053 \pm 0.001$ \\
Internal Package & $0.055 \pm 0.002$ & - & $0.052 \pm 0.001$ & - & $0.59 \pm 0.102$ \\
\hline
\end{tabular}

\section{ii) FTIR Spectrum Study}

A variety of flexible packaging materials are used for packing biscuits due to advantages such as functionality, lower cost, printability, light weight, savings in freight and other such factors. Biaxially oriented polypropylene (BOPP) film,commonly known as OPP, is widely used. For higher quality products, duplex OPP or OPP combinations (pearlised or metallised) such as OPP/PE, OPP/PET, etc. are used (http://www.envis-icpe.com/ icpefoodpackaging/pdfs/ 7_bakery.pdf). FTIR spectrum study of packaging materials ing region) of polyethylene (Shimadzu, 2001). This stretch matches with a stretch in $3150-2780 \mathrm{~cm}^{-1}$ absorbance region of LLDPE and BOPP as per manufacturer's packagimg material specification used as standard reference material. The $1800-1650 \mathrm{~cm}^{-1}$ absorbance region exhibits IR absorption from a wide variety of double bonded functional groups. Below $1500 \mathrm{~cm}^{-1}$ absorbance region is termed as the fingerprint region of characteristic functional groups (Shimadzu, 2001). Due to crystalinity of LLDPE, the split and additional peaks in the absorbance region 1464 and $719 \mathrm{~cm}^{-1}$ were 


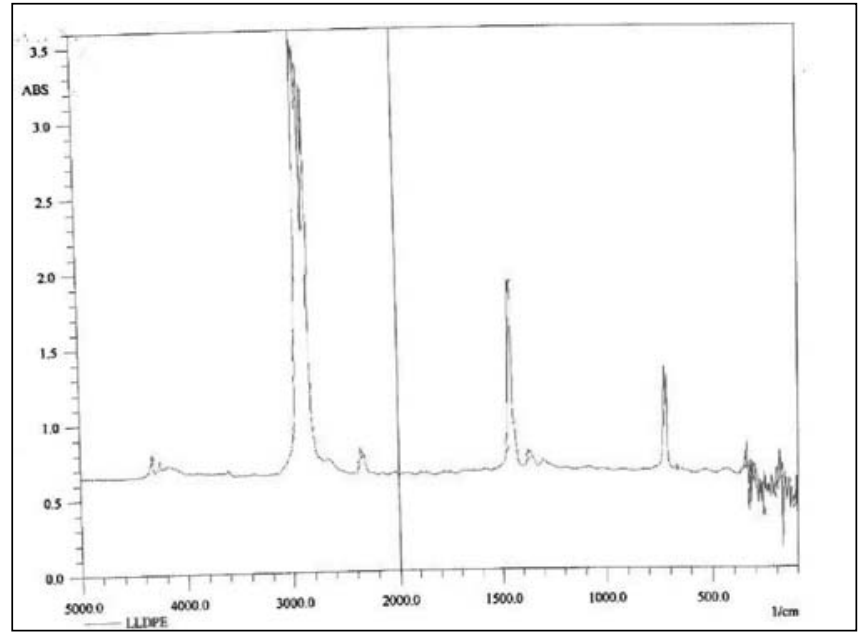

a

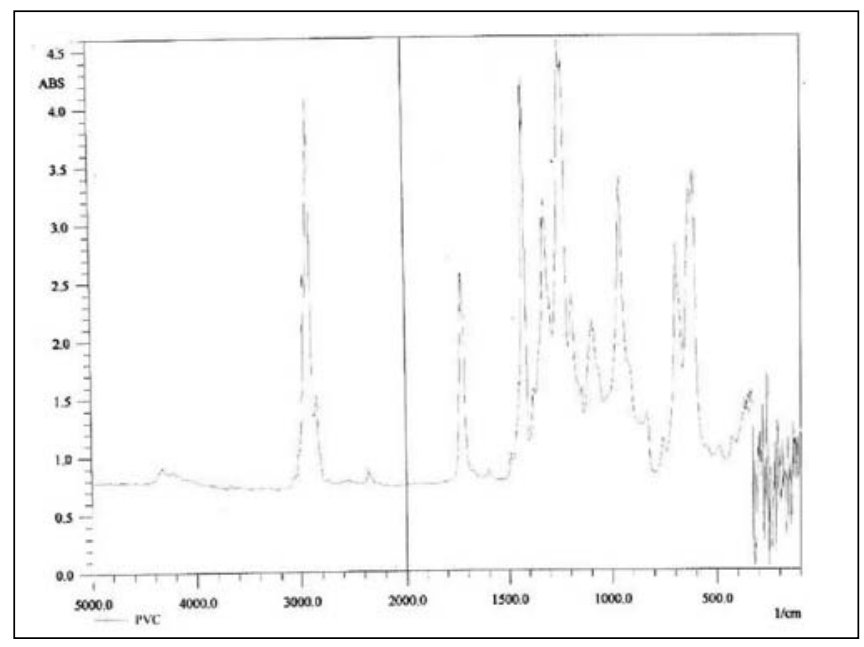

C

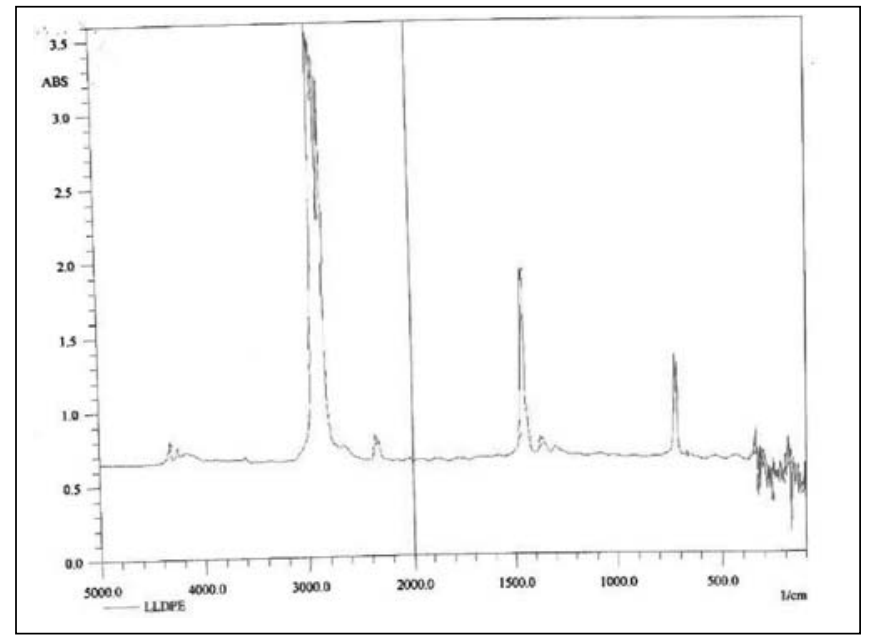

b

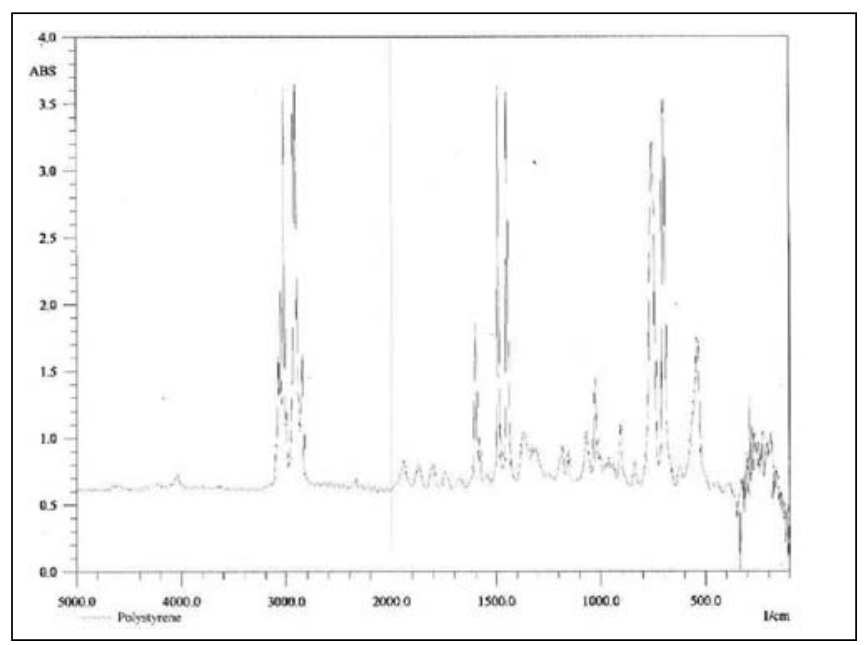

d

Fig. 3: FTIR Spectra of Reference Packaging Materials of Local Manufacturer - (a) BOPP, (b) LLDPE, (c) PVC and (d) Polystyrene.

observed (O'Keefe, 2004). From all these studies of stretching regions it can be concluded that the external packaging materials of these five brands of local biscuits might be composed of BOPP, vacuum coated with aluminum and later on laminated with thermosetting LLDPE in the inner side (BOPP/Al/LLDPE).

Studying FTIR spectra of internal packages of LB, LD and LE, it has been found from figure 5 that internal packages of LB and LD have almost same patterns although LD has some more hazy peaks. LB and LD contain cellulose paper as inner package. Cellulose package of LD is wax coated. On the contrary, inner package of LE shows the same two peaks between $3100-2800 \mathrm{~cm}^{-1}$ absorbance region as polystyrene.
When the side group on the methylene chain is an aromatic ring, the infrared spectrum becomes a combination of methylene and mono-substituted aromatic ring peaks. The polystyrene spectrum has dominant peaks at 2926 and 2851 $\mathrm{cm}^{-1}$ absorbance region from the methylene stretches. The out-of-plane $\mathrm{C}-\mathrm{H}$ bends of the aromatic rings are intense at 698 and $756 \mathrm{~cm}^{-1}$ absorbance region. The aromatic ring breathing modes appear at 1601,1493 and $1452 \mathrm{~cm}^{-1}$ absorbance region. The peaks at 3082, 3061 and $3027 \mathrm{~cm}^{-1}$ absorbance region are absorptions from the aromatic $\mathrm{C}-\mathrm{H}$ stretches (O'Keefe, 2004). But inner package of LE shows some more broad bends in $3850-3380 \mathrm{~cm}^{-1}$ absorbance region that might arise from a small amount of water (Shimadzu, 2001). 


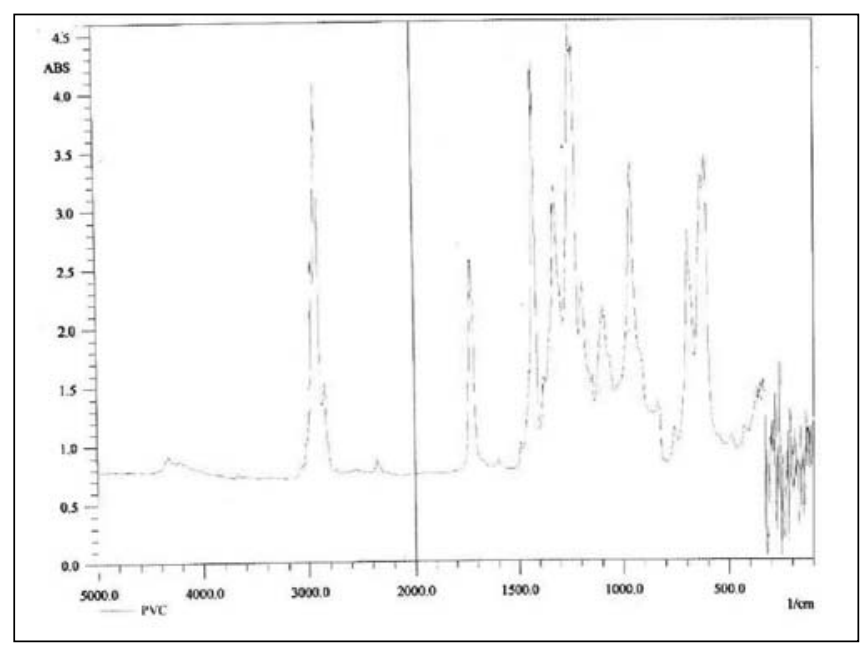

a

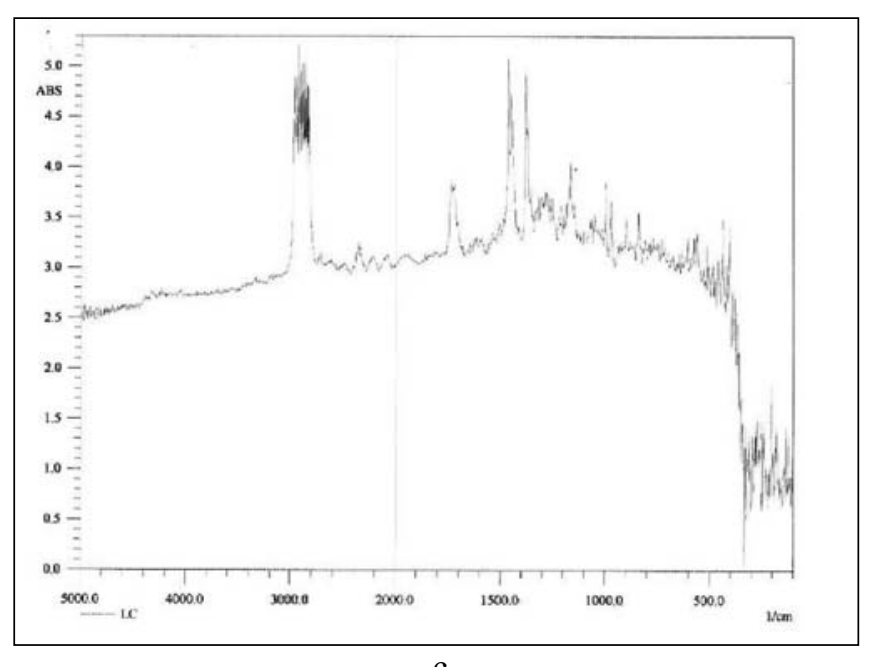

c

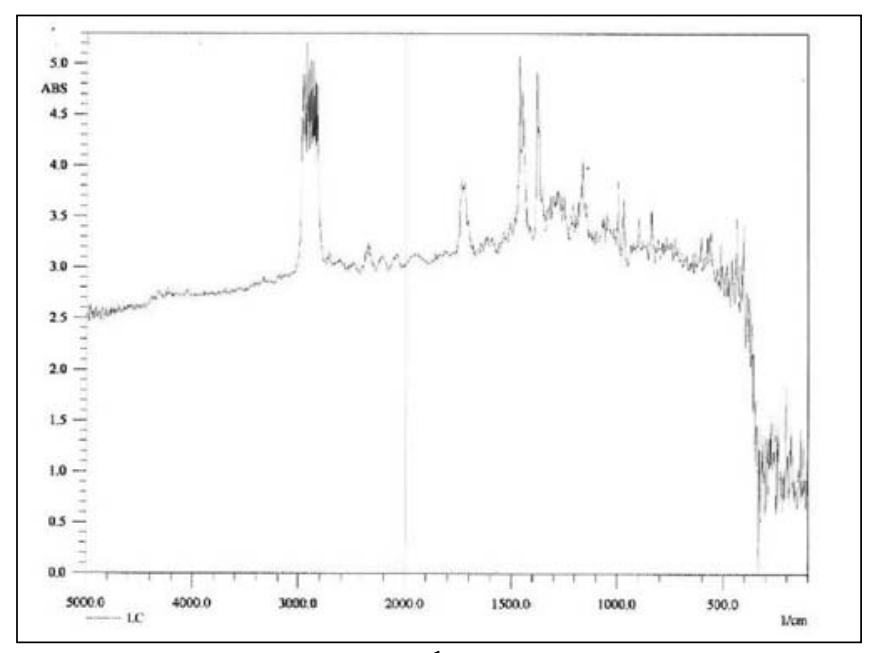

b

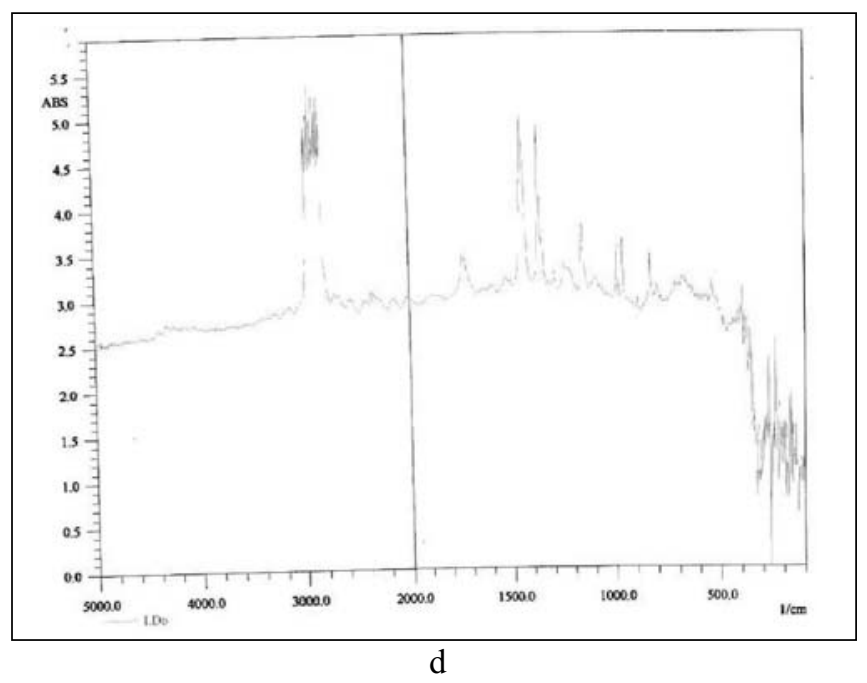

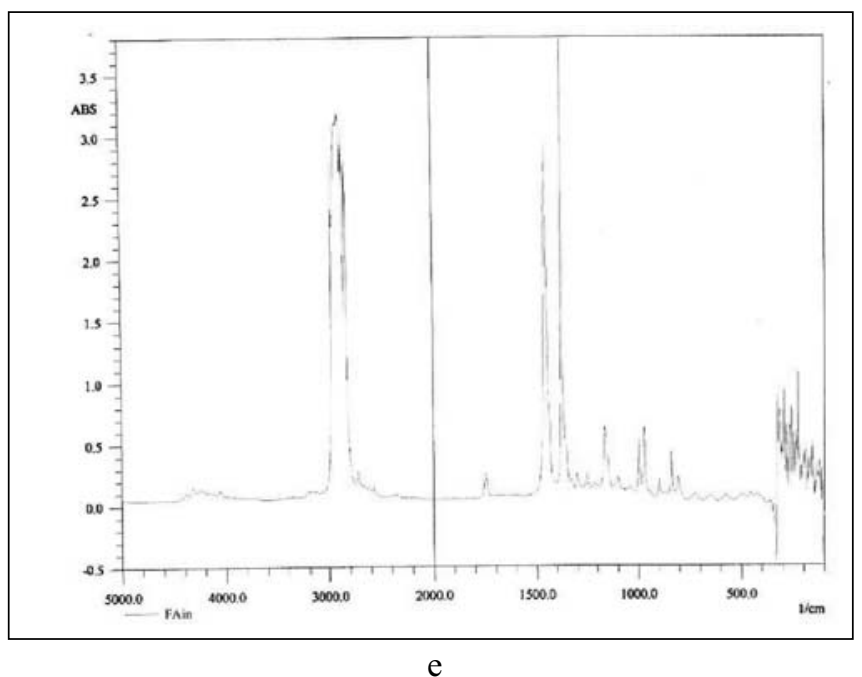

Fig. 4: FTIR Spectra of External Packaging Materials of 5 Brands of Local Biscuits - (a) LA, (b) LB, (c) LC, (d) LD and (c) LE. 


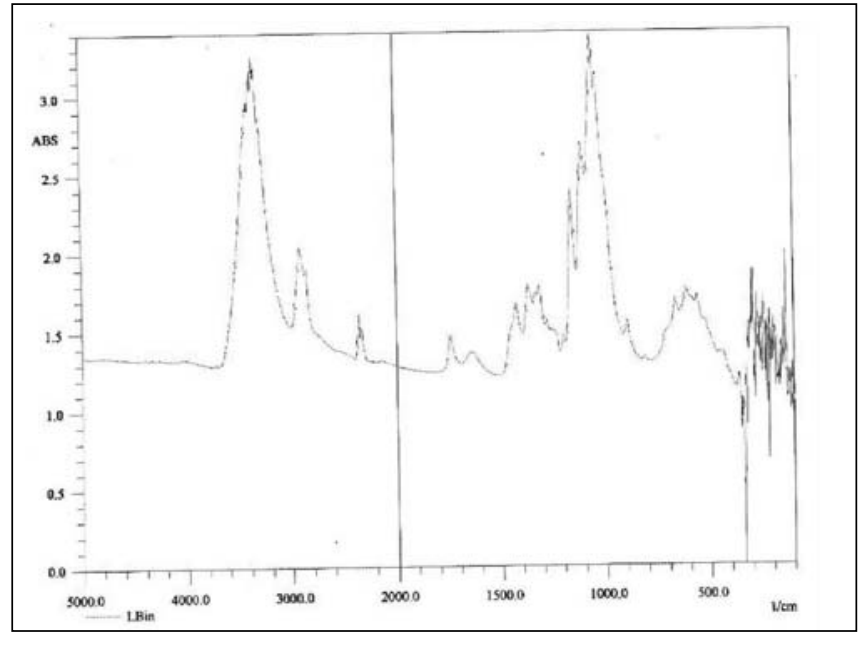

a

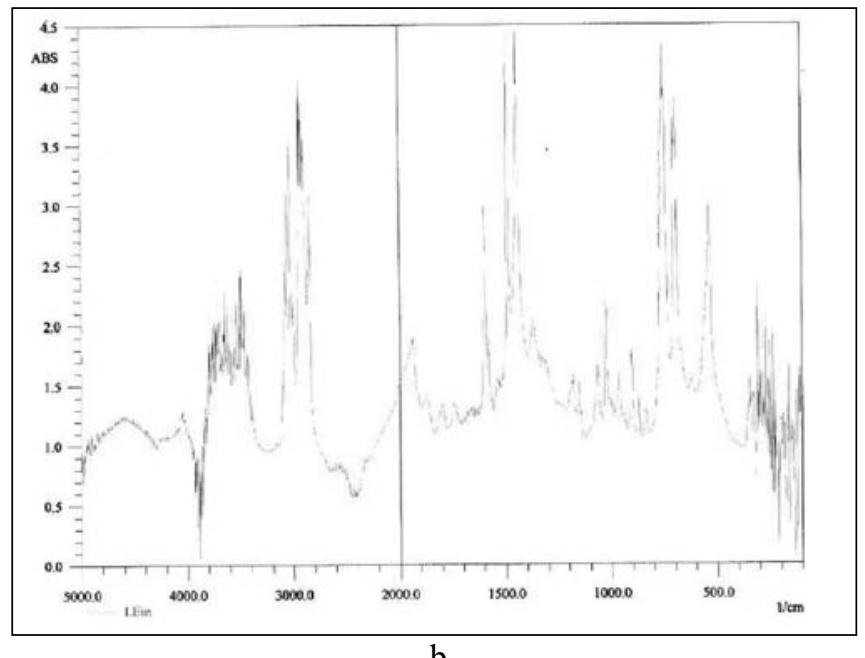

b

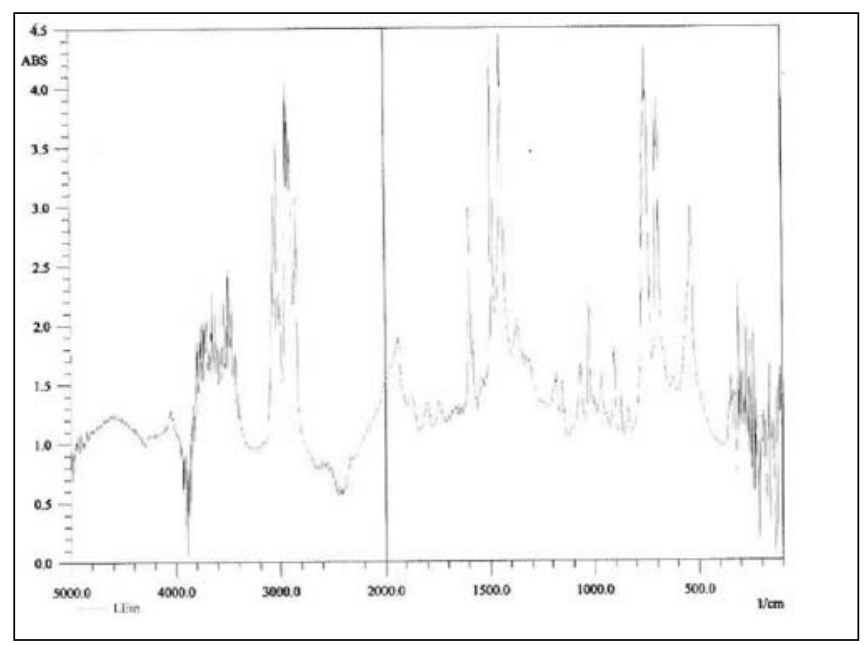

C

Fig. 5: FTIR Spectra of Internal Packaging Materials of 3 Brands of Local Biscuits - (a) LB, (b) LD and (c) LE
Unlike external packaging of local biscuits, five brands of foreign biscuits do not contain almost same outer packaging materials. FTIR spectra of external packages of FA and FB show the same patterns that match with FTIR spectrum of BOPP (Figure 6). Both FA and FB have bends in 3000-2800 $\mathrm{cm}^{-1}$ absorbance region as BOPP that is the $\mathrm{C}-\mathrm{H}$ stretching region (Shimadzu, 2001). The methyl peaks appear at 2962/2952 (split peak), 2868 and $1377 \mathrm{~cm}^{-1}$ absorbance region. A methyl deformation is also overlapped with the methylene deformation, and this peak has shifted slightly to $1458 \mathrm{~cm}^{-1}$ absorbance region. FC and FD both have hard paper as outer package through which infrared ray can not pass. So IR spectrum analysis of these packages could not be done and only some hazy noises have been observed. FTIR spectrum of FE shows the same stretching regions as external packages of local biscuits. Studying all the peaks of this package, it can be assumed that it might also be composed of BOPP, Vacuum coated with aluminium and later on laminated with thermosetting LLDPE in the inner side (BOPP/Al/ LLDPE).

Different companies use different materials as internal packages of the foreign biscuits used in this study. Inner packet of FA shows same FTIR spectrum as BOPP (Figure 7). On the contrary, FTIR spectra of inner packets of FC and FD show almost same pattern as those of outer packaging if local biscuits. Thus these might be composed of BOPP/A1/LLDOE. Again internal packet of FE gives the same FTIR spectrum as PVC. The IR spectrum of PVC has a strong bend with a maximum at $1255 \mathrm{~cm}^{-1}$ absorbance region. This is due to $\mathrm{C}$ wagging when the adjacent $\mathrm{C}$ atom has a chlorine atom attached. A methine wag can be observed at $1200 \mathrm{~cm}^{-1}$ absorbance region. The methylene asymmetric stretch peaks at $2912 \mathrm{~cm}^{-1}$ absorbance region with a methine C-H stretch peaking at $2970 \mathrm{~cm}^{-1}$ absorbance region (O'Keefe, 2004). The C-Cl stretch vibrations in the vicinity of $600-700 \mathrm{~cm}^{-1}$ absorbance region (Shimadzu, 2001). The methylene scissors deformation is split at 1435 and $1427 \mathrm{~cm}^{-1}$ absorbance region (O'Keefe, 2004).

Nowadays most of the biscuits are packed in flexible laminates of composite structures, where every component fulfills a specific function. These laminates have desirable properties such as moisture barrier, gas barrier, heat sealability, printability characteristics, high production and overall economy (http://www.envis-icpe.com/icpefoodpackaging/ pdfs/7_bakery.pdf). 


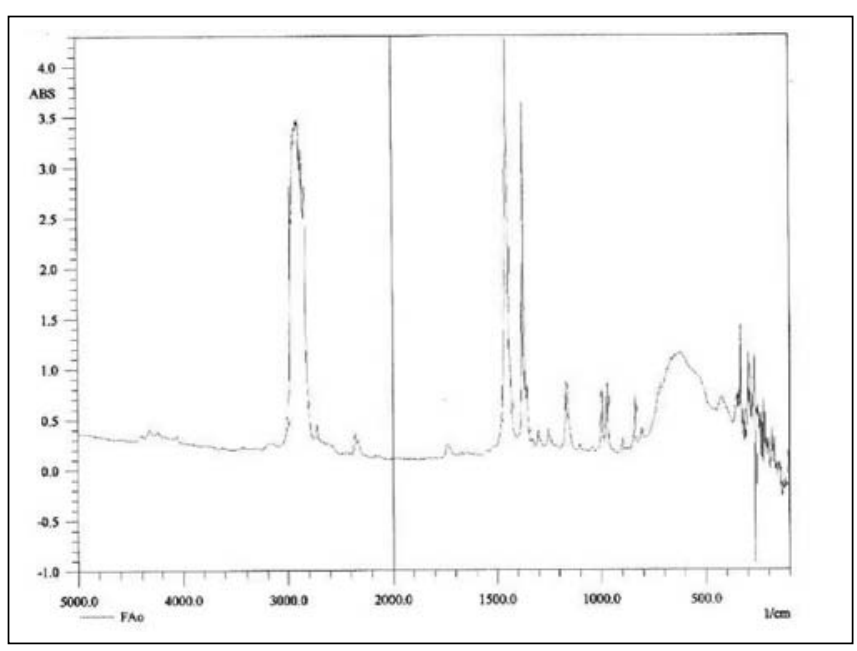

a

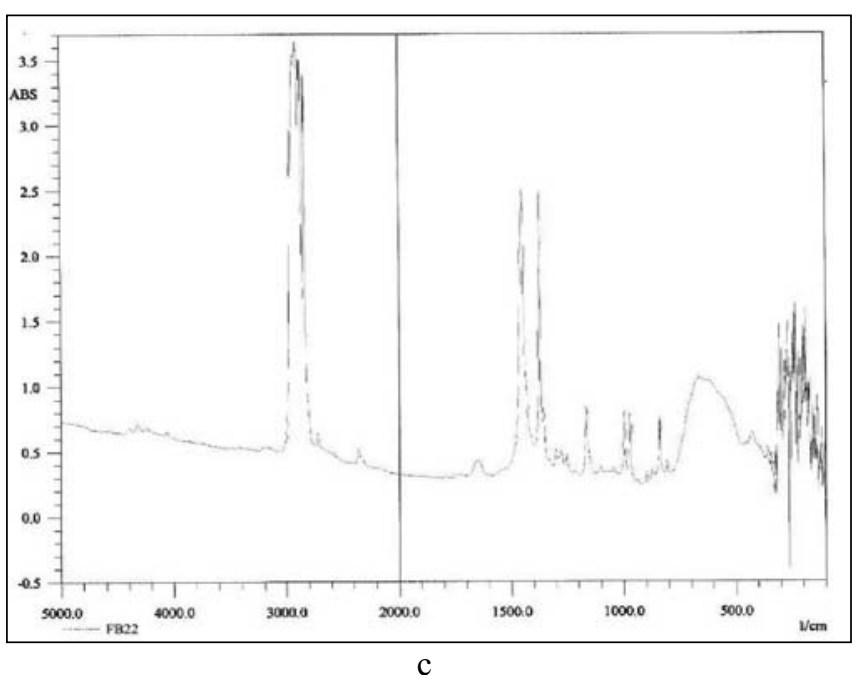

$\mathrm{c}$
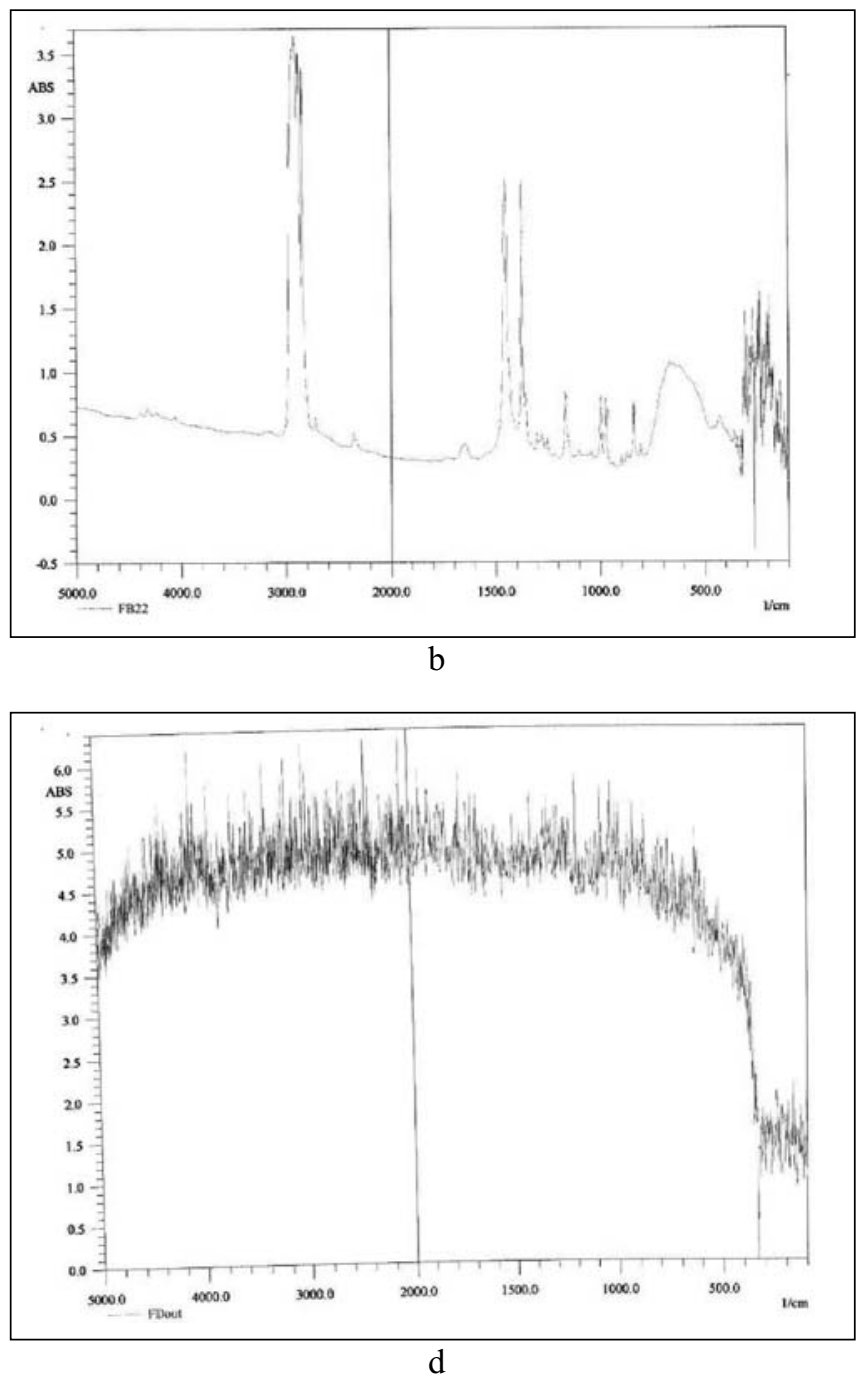

d

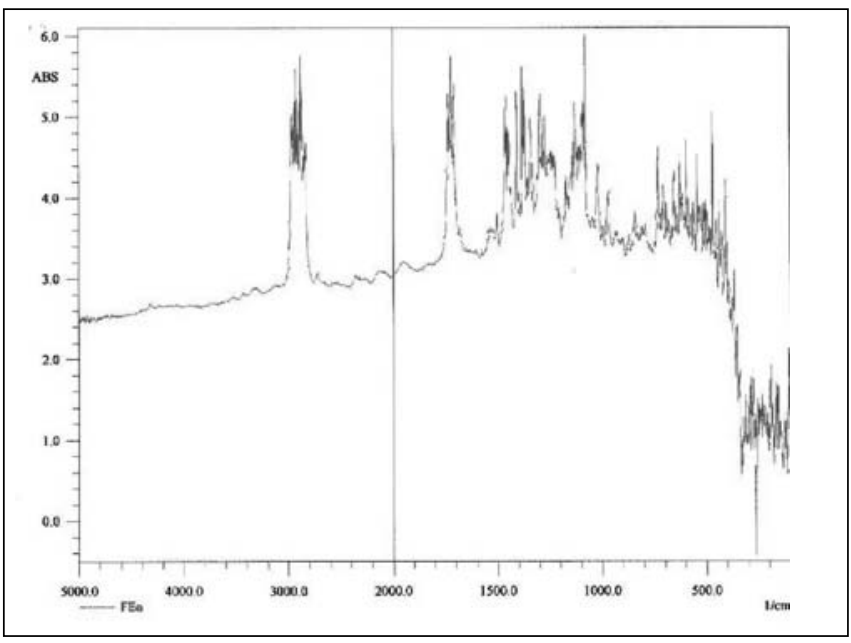

e

Fig. 6: FTIR Spectra of External Packaging Materials of 5 Brands of Foreign Biscuits - (a) FA, (b) FB, (c) FC, (d) FD and (e) FE. 


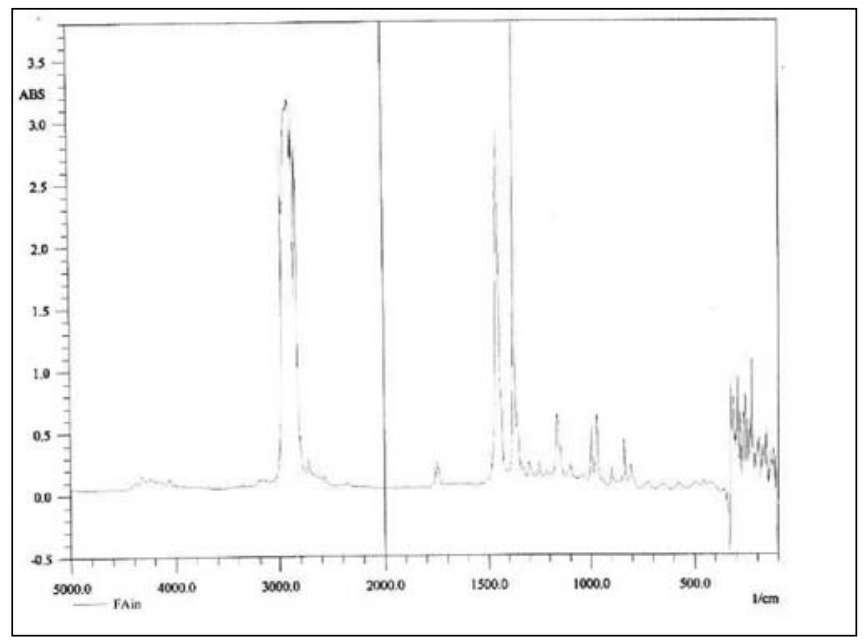

a

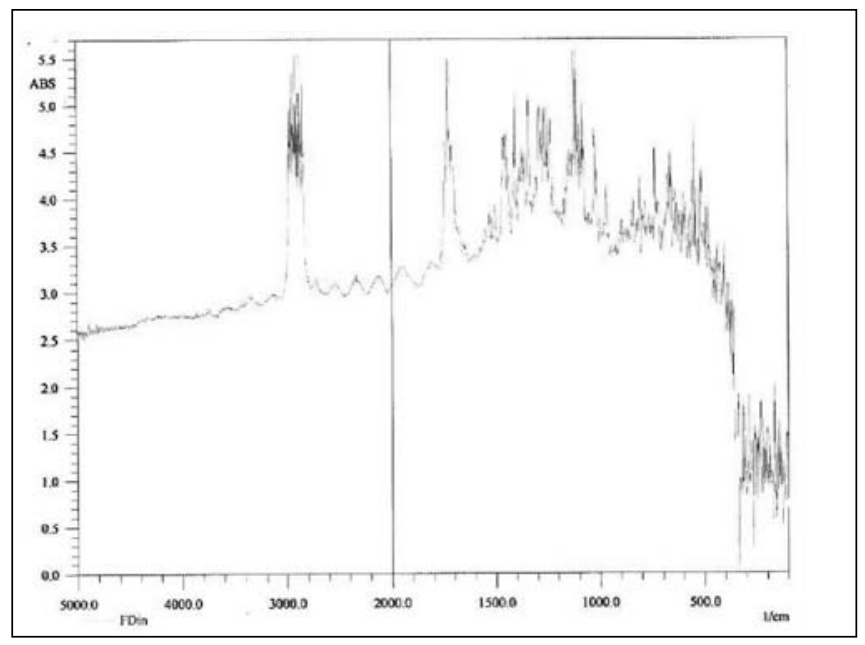

c

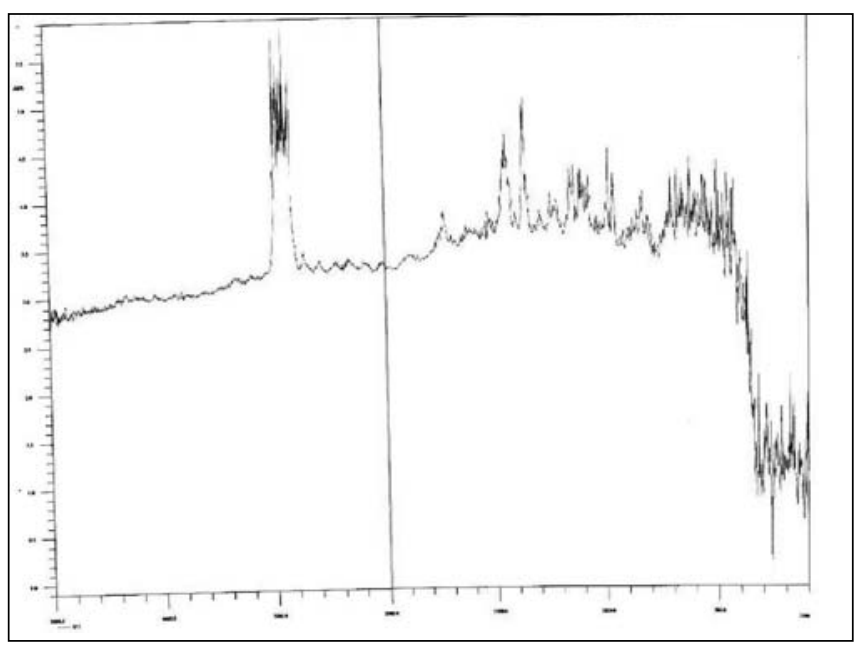

b

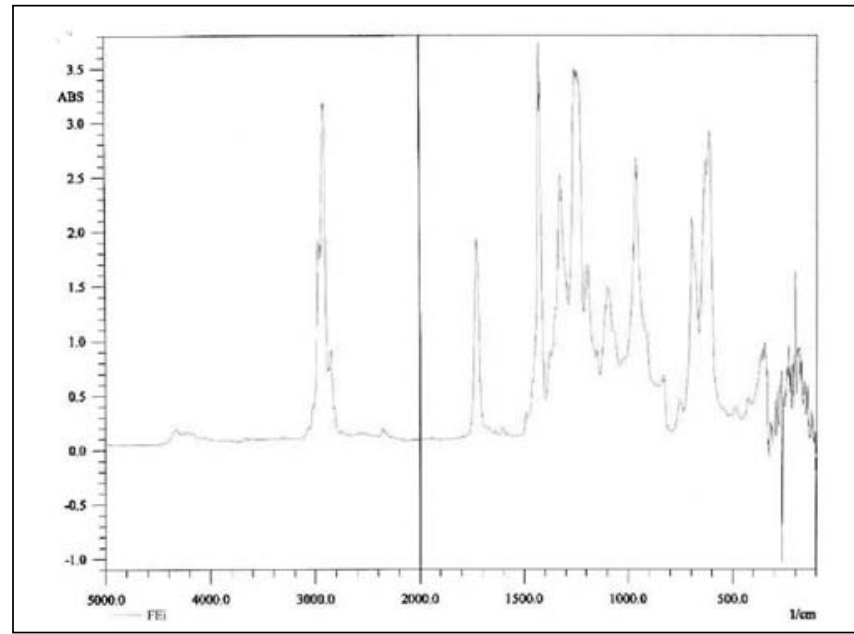

d

Fig. 7: FTIR Spectra of Internal Packaging Materials of 4 Brands of Foreign Biscuits - (a) FA, (b) FC, (c) FD and (d) FE

\section{Conclusion}

The study focuses on the effect of critical factors on shelf life of biscuits. Shelf-life of biscuits depends on the initial quality and hygiene of the raw materials used. Comparative study of sensory evaluation between local and foreign biscuits shows that almost all the biscuits are acceptable except the local biscuit, LB (overall acceptance score 4.85 \pm 1.67 ). Packaging material study reveals that local manufacturers use almost similar type of packaging material to pack biscuits. On the other hand, a wide variation in packaging materials is notable in case of foreign packed biscuits. Results also show that there is a correlation between moisture, water activity, sensory quality (crispiness, texture, and flavor) and packaging technology on shelf life of the studied samples. This relationship gives an idea of the raw materials quality, processing and packaging technology of the studied biscuit samples. It can be summarized from the whole study that quality raw materials, appropriate processing and packaging material will provide an extended shelf life of biscuits by minimizing quality deterioration.

\section{Acknowledgement}

This paper is an outcome of R \& D project work "Studies on the Packaging Materials used in Different Bakery Products (Bread, Biscuit \& Chanachur) of the Local Confectionaries 
in the light of HACCP" of IFST, BCSIR, Dhaka. The instruments used in this work have been supported by an ADP project funded by the Ministry of Science and Information and Communication Technology, Government of Bangladesh. We are grateful to the BCSIR authorities for providing the scope to conduct the study and to Mr. Abdul Latif, Ex-Chief Scientific Officer, IFST \& Dr. Mamtaz Dowlatana, Director, BCSIR. Both of them were Project Directors of the above-mentioned ADP project. We are also grateful to Dr. Barun Kanti Saha, SSO and Abdur Rahim, JEO, IFST. Both were sensory test panelists of this work.

\section{References}

Ackermann P., Jagerstad M. and Ohlsson T. (1995). Foods and Packaging Materials - Chemical Interactions. 1st Ed. (The Royal Society of Chemistry, UK), pp 33, 34, 65, 137.

Ball C. O. (1960). Here are effects on color changes in packaging of fresh meat cuts. Natl. Provisional 143(47): 10 $-12$.

Dunn J. A. and Bailey C. H. (1928). Factors affecting checking in biscuit, Cer.Chem. 5:395 - 430.

Katz E. E and Labuza T. P. (1981). Effect of Water Activity on the Sensory Crispness and Mechanical Deformation of Snack Food Products. J. Food Sci., 46: 403-409.

Labuza T. P. and Contreras-Medellen R. (1981). Cereal Foods World 26: pp 335.

Lallemand Inc. (2000). Cookie and Biscuit Production. Lallemand Baking Update. 2(19).

Lewicki P. P. (2004). Water as the determinant of food engineering properties: A review. J. Food Eng., 61: 483 495 .

Lewicki P. P., Jakubczyk E., Marzec A., Cabral M. C., Pereira P. M. (2004). Effect of water activity on mechanical properties of dry cereal products. Acta Agro. 4(2): 381-391.

Man and Jones (1994). Shelf life evaluation of foods (Blackie academic and professional, Chapman \& Hall, Glasgow, UK), pp 203.
Manley D. J. R. (1998). Biscuit, Cookies and Crackers Manufacturing, Manual 6: Packaging and Storing. 3rd Ed. (Woodhead Publishing Limited, Cambridge, England), pp 5.

Mathlouthi M. (2001). Water content, water activity, water structure and the stability of foodstuffs. Food Control, 12: 409 - 417

Nieuwenhuijzen N. P. V., Martin C. P, Meinders M. B. J., Tromp R. H., Hamer R. J., and Vile T. V. (2008). Water Content or Water Activity: What Rules Crispy Behavior in Bread Crust? J. Agric. Food Chem., 56(15): 6432-6438.

O'Keefe J. F. (2004). Identification of Polymers by IR Spectroscopy. Rubber World, pp 1: 6.

Ooraikul B. and Stiles M. E (1991). Modified Atmosphere Packaging of Food. 1st Ed. (ELLIES HORWOOI, London), pp $28 \& 30$.

Peryam D. R. and F. J. Pilgrim (1957). Hedonic scale Method of measuring food preference. Food Technol. II: 9-14 (suppl.).

Peter F. and Axtell B. (1993). Appropriate Food Packaging, Publ. Transfer of Technology for Development. Amsterdam, International Labor office, Geneva.

Roudaut G., Dacremont C., Le Meste M., Pamies B. V. and Mitchell J. R. (2000). Understanding the texture of Low Moisture Cereal Products: Mechanical and Sensory Measurements of Crispness. J. Sci. and Food Agri., 80: 1679-1685.

Roudaut G, Dacremont C. and Le Meste M., Pamies B. V. and Mitchell J. R. (1998). Influence of water on the Crispness of cereal-Based foods: Acoustic, Mechanical and Sensory Studies. J. Tex. Stud., 29(2): 199-213.

Sauvageot F. and Blond G. (1991). Effect of water activity on crispness of breakfast cereals. J. Text. Stud. 22: 423 $-429$.

Settle F. S. (1997). Handbook of Instrumental Techniques for Analytical Chemistry, 2nd ed., (Prentice Hall, New Jersey), pp 270. 
Seymour S. K. and Hamann D. D. (1988). Crispness and crunchiness of selected low moisture foods. J. Text. Stud. 19: 79 - 86.

Shimadzu (2001). General Operation Guide for Shimadzu FTIR 8000 Series (FTIR-8400/8900), pp 21, 22.

Steele R.(ed.) (2004). Understanding and measuring the shelf-life of food. Woodhead Publishing Ltd. Cambridge. U.K., pp 50.

Toledo R.T. (1991). Fundamentals of Food Process Engineering, 2nd ed., Chapman \& Hall, New York (NY), USA, pp 456-506.
Van Den Berg C. and Bruin S. (1981). Water activity and its estimation in food: Systems Theoretical aspects. In "Water Activity: Influences on Food Quality." ed. By L.B. Rockland and G.F. Stewart. Academic Press, London, pp.4-8.

Wade P. (1988). Cookies and Crackers, Vol. 1. The Principles of the Craft, Elsevier Applied Science Publisher Ltd., Essex, England. Chapter: 4.

Worobo, R. and Padilla-Zakour, O. (1999) Water activity: another critical factor for safety of food products. Venture. 1(4): 1 - 5.

http://www.envis-icpe.com/icpefoodpackaging/pdfs/7_bakery.pdf

Received : July 13, 2010;

Accepted : August 25, 2011 